\title{
Diagnosis of spinal muscular atrophy in an SMN non-deletion patient using a quantitative PCR screen and mutation analysis
}

\author{
D W Parsons, P E McAndrew, P S Allinson, W D Parker Jr, A H M Burghes, T W Prior
}

$T$ W Prior

Division of Genetics, Children's Medical Center, University of Virginia Health Sciences Center, Charlottesville, Virginia 22908, USA

P S Allinson

Department of Neurology, Division of Pediatric Neurology, University of Virginia Health Sciences Center, Charlottesville, Virginia 22908, USA W D Parker Jr

Departments of Neurology and Medical Biochemistry, The Ohio State University College of Medicine and Department of Molecular Genetics, College of Biological Sciences, The Ohio State University, Columbus, Ohio 43210, USA

A H M Burghes

Correspondence to: Dr Prior.

Received 14 November 1997 Revised version accepted for publication 7 January 1998 $\mathrm{SMN}^{\mathrm{T}}$ gene is not detectable in $\sim 95 \%$ of SMA duced vaginal delivery because of non-

\begin{abstract}
Department of Pathology, The Ohio State University College of Medicine, 121 Hamilton Hall, 1645 Neil Avenue, Columbus, Ohio 43210, USA

D W Parsons

P E McAndrew

Abstract

We report a child with clinical findings consistent with Werdnig-Hoffmann disease (spinal muscular atrophy type I) who was found not to have the homozygous absence of the survival motor neurone $\left(\mathrm{SMN}^{\mathrm{T}}\right)$ gene observed in $\sim 95 \%$ of spinal muscular atrophy patients. A quantitative PCR based dosage assay for $\mathrm{SMN}^{\mathrm{T}}$ copy number showed that this patient possessed a single copy of the $\mathrm{SMN}^{\mathrm{T}}$ gene. Heteroduplex and sequence analysis of the remaining copy of $\mathrm{SMN}^{\mathrm{T}}$ showed a 2 base pair deletion within exon 4 which produces a frameshift and premature termination of the deduced $S M N^{\mathrm{T}}$ protein. This protocol of initial $\mathrm{SMN}^{\mathrm{T}}$ gene dosage analysis followed by mutation detection allows identification of SMA compound heterozygotes (patients lacking one copy of $\mathrm{SMN}^{\mathrm{T}}$ and having another mutation in their other copy), thereby increasing the sensitivity of SMA molecular diagnosis. (F Med Genet 1998;35:674-676)
\end{abstract}

Keywords: spinal muscular atrophy; survival motor neurone gene; quantitative PCR

Proximal spinal muscular atrophy (SMA) is an autosomal recessive neuromuscular disorder characterised by destruction of $\alpha$ motor neurones in the anterior horn of the spinal cord. SMA has an estimated incidence of 1 in 10000 live births, with a carrier frequency of $\sim 1$ in 50 people. ${ }^{1}$ Childhood onset SMA is classified into three groups on the basis of age of onset and clinical course ${ }^{2}$; type I SMA (Werdnig-Hoffmann disease) is the most severe form, with onset before the age of 6 months and death generally occurring within the first two years. In 1995, three cDNAs that detect deletions in the SMA critical region on 5q12-13 were reported. ${ }^{3-5}$ One of these, the survival motor neurone (SMN) cDNA, is encoded by two nearly identical genes, telomeric SMN $\left(\mathrm{SMN}^{\mathrm{T}}\right)$ and centromeric SMN $\left(\mathrm{SMN}^{\mathrm{C}}\right)$, which are distinguished only by single base changes in exons 7 and 8 . Exon 7 of the patients. ${ }^{3}$ In those SMA patients retaining $S M N^{\mathrm{T}}$, a limited number of other small $S M N^{\mathrm{T}}$ mutations have been identified. ${ }^{36-13}$

\section{Case report}

The proband, a male infant, was born to nonconsanguineous parents at 38 weeks by in- progression. The mother was 30 years old and the father was 32 years old at the time of birth, and their family history was unremarkable. Both the pregnancy and delivery were uncomplicated.

At 4 months of age, the patient was referred to a paediatric neurologist because of diffuse hypotonia and weakness. On examination, he was unable to lift his head or his legs off the bed. More movement was seen in the upper extremities; he was able to flex his arms and place his hands in his mouth bilaterally. No evidence of fasciculations or atrophy was noted, and no deep tendon reflexes were observed. Laboratory values, including creatine kinase, plasma amino acids, and urine organic acids, were within normal limits.

Nerve conduction studies of the right upper extremity showed extremely low amplitude motor responses. Repetitive stimulation of the right ulnar nerve at $2 \mathrm{Hertz}$ and $50 \mathrm{Hertz}$ failed to show a decremental or incremental response. Needle examination of selected limb muscles showed significantly reduced recruitment of motor unit potentials in all muscles examined; occasional fibrillations were seen in several muscles. These studies were interpreted as indicating electrophysiological evidence of a widespread motor neuropathic process, compatible with a clinical diagnosis of spinal muscular atrophy. No evidence of a myopathy or disorder of neuromuscular transmission was identified.

At 7 months of age, the patient suffered cardiopulmonary arrest. After resuscitation, a head CT was obtained that showed no bleeding or oedema. His neurological examination was notable for fixed pupils, negative corneal reflexes, oculocephalic reflexes, negative cold calorics, no cough reflex, no gag reflex, and no response to pain. It was clear that he had sustained a severe anoxic brain injury, and his parents agreed to discontinuation of support Necropsy was declined.

\section{Results}

The clinical history, neurological examination, and nerve conduction studies were judged to be consistent with a motor neurone disease, most likely spinal muscular atrophy.

However, direct genetic testing for SMA did not show the homozygous absence of the $\mathrm{SMN}^{\mathrm{T}}$ gene which is found in $-95 \%$ of SMA patients. ${ }^{314}$ Owing to the strong clinical suspicion that this patient had SMA, more extensive molecular studies were undertaken.

A quantitative PCR assay for accurately determining $\mathrm{SMN}^{\mathrm{T}}$ gene copy number has 


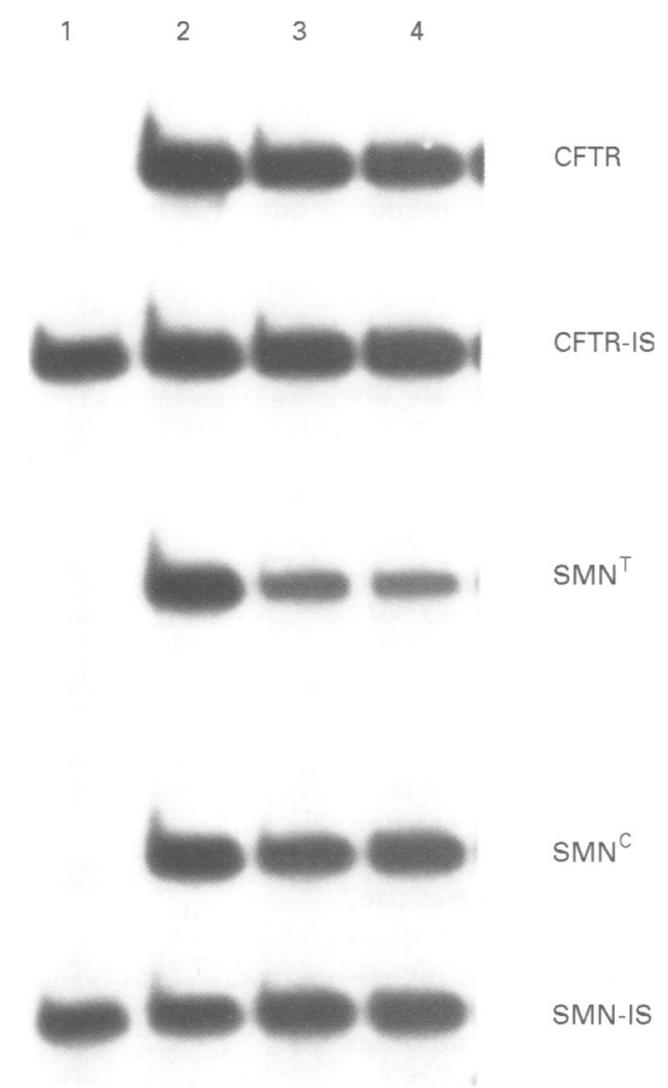

Figure 1 Dosage analysis of the $S M N^{T}$ gene in the patient and controls. Autoradiograph of competitive $P C R$ products digested with DraI and electrophoresed on a 6\% denaturing polyacrylamide gel. Equal amounts of genomic DNA were added to each reaction, except for the blank (lane 1), which contained no genomic DNA but only synthesised internal standards for the SMN and CFTR genes (SMN-IS and CFTR-IS). The SMN ${ }^{T} / C F T R$ ratio in the patient (lane 4) is half that of the normal control (lane 2) and equal to that of the SMA carrier control (lane 3), indicating that the patient has only a single copy of SMN ${ }^{T}$.

been developed in our laboratory. ${ }^{10}$ Although this assay has primarily been used for determination of SMA carrier status, it is also valuable for identification of patients with clinical features consistent with SMA who are likely to be compound heterozygotes (patients with one $\mathrm{SMN}^{\mathrm{T}}$ gene lost to deletion or sequence conversion and one $\mathrm{SMN}^{\mathrm{T}}$ gene containing another type of mutation). This assay uses an

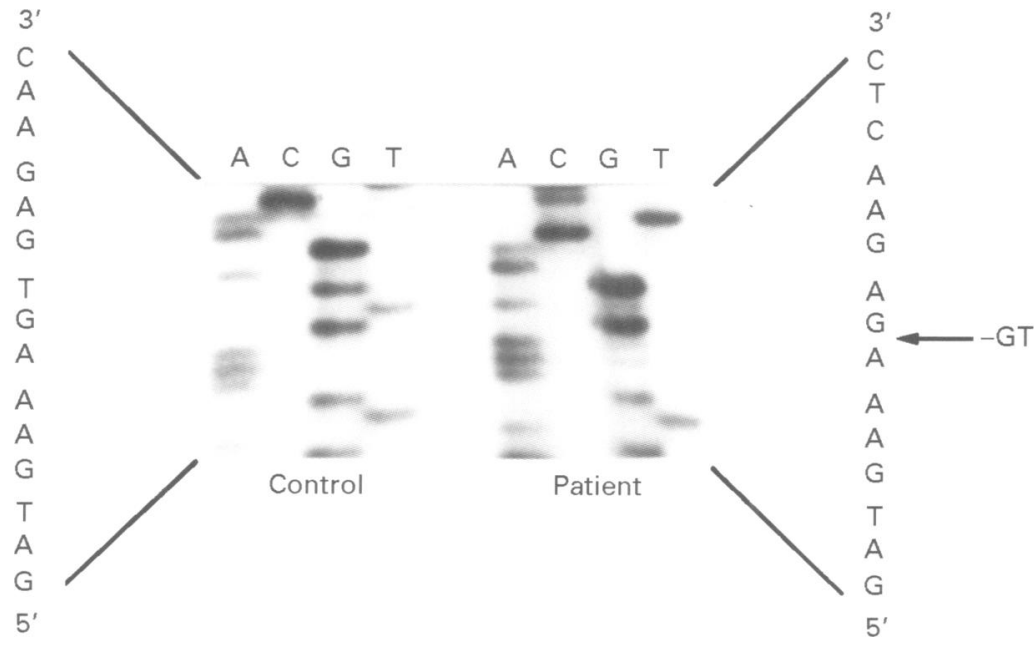

Figure 2 Sequence analysis of patient and control SMN $N^{T}$ exon 4 subclones. The patient has a 2 base pair deletion (-GT) of nucleotides 542-543, which produces a frameshift and premature termination of the deduced $S M N^{T}$ protein. exon of the cystic fibrosis transmembrane regulator (CFTR) gene as a standard to determine the copy number of the $S M N^{T}$ and $S M N^{C}$ genes, and incorporates the use of two internal standards (SMN-IS and CFTR-IS) to monitor the efficiency of the PCR reaction and to ensure that equal amounts of target genomic DNA are added to each tube. Since this test uses CFTR as the standard for determination of $S M N^{\mathrm{T}}$ copy number, the significant limitation of using the $S M N^{C}$ gene (whose copy number varies in both patients and controls) as a reference is avoided. Dosage analysis of the $\mathrm{SMN}^{\mathrm{T}}$ gene in the proband showed that he possessed only a single copy of $\mathrm{SMN}^{\mathrm{T}}$ (fig 1).

Heteroduplex analysis was then used to screen for sequence variations in the nine exons of the remaining copy of $S M N^{\mathrm{T}} .{ }^{10}$ An abnormal band was identified in exon 4 of SMN. Sequence analysis of patient exon 4 subclones showed a two base pair deletion of nucleotides 542-3 (GT) of the SMN gene (fig 2). The deletion results in a frameshift and premature termination codon shortly downstream, predicting an SMN protein product containing eight altered amino acids before truncation. In order to determine whether the variant exon 4 sequence was contained within $S M N^{\mathrm{T}}$ or $S M N^{C}$, the patient's lymphocyte RNA was amplified by RT-PCR using an exon 4 sense primer and an exon 8 antisense primer, then subcloned and sequenced. Patient subclones containing $S M N^{\mathrm{T}}$ were identified by restriction enzyme digestion, and sequence analysis of these clones confirmed that the mutant transcripts were derived from $S M N^{\mathrm{T}}$. These results indicate that this type I SMA patient had two different $S M N^{\mathrm{T}}$ mutations: one $\mathrm{SMN}^{\mathrm{T}}$ allele was deleted or converted, while the other contained a two base pair deletion in exon 4 .

\section{Discussion}

The fact that exon 7 of the $\mathrm{SMN}^{\mathrm{T}}$ gene is not detectable in $-95 \%$ of SMA patients has allowed the development of an effective PCR based assay for the diagnosis of SMA. ${ }^{3}{ }^{14} \mathrm{How}-$ ever, the 1 in 20 SMA patients who do not homozygously lack the $S M N^{\mathrm{T}}$ gene will be missed using this test. The proband, a male infant with clinical findings consistent with a diagnosis of type I SMA (Werdnig-Hoffmann disease), is one of these patients. He inherited one deleted or converted copy of the $S M N^{\mathrm{T}}$ gene and one copy containing a different mutation, a 2 base pair deletion in exon 4 which causes a frameshift and would be predicted to result in a truncated $S M N^{T}$ protein.

We have previously reported a quantitative PCR based assay for determination of $S M N^{T}$ gene copy number. ${ }^{10}$ In addition to allowing the molecular diagnosis of SMA carriers, this test also enables us to screen patients with SMA-like clinical findings efficiently in order to help distinguish SMA compound heterozygotes from non-5q cases. Once an SMA-like patient with one copy of the $S M N^{T}$ gene has been identified, the probability of a 5q SMA diagnosis is increased significantly. However, it is possible that the subject may be an SMA 
carrier whose symptoms are caused by another neuromuscular disorder. Therefore, we recommend that mutation screening of the remaining copy of $S M N^{\mathrm{T}}$ be carried out. By using this initial quantitative screen for $\mathrm{SMN}^{\mathrm{T}}$ gene copy number, the number of patients who require mutation analysis can be drastically reduced. In our experience, $\sim 10 \%$ of the patients referred to our diagnostic laboratory for SMA testing who are not homozygously lacking the $S M N^{\mathrm{T}}$ gene retain a single copy of $S M N^{\mathrm{T}}$. In the remaining $90 \%$ of these SMA-like patients, the $\mathrm{SMN}^{\mathrm{T}}$ gene dosage is normal and $5 \mathrm{q}$ SMA is effectively ruled out as a diagnosis; in these cases the physician should consider other neuromuscular diseases. We have used this combination of an initial $\mathrm{SMN}^{\mathrm{T}}$ dosage assay and mutation detection to identify two other small mutations in the $\mathrm{SMN}^{\mathrm{T}}$ gene, a missense mutation (S262I) and an 11 base pair duplication in exon $6 .{ }^{710}$ Once a specific $S M N^{\mathrm{T}}$ mutation has been identified in a family, other family members can be accurately diagnosed and appropriately counselled.

This screening strategy would not be as useful in diagnosing SMA in consanguineous families or in groups exhibiting a significant founder effect, since subjects who are homozygous for a non-deletion $\mathrm{SMN}^{\mathrm{T}}$ mutation would be more common in those instances. ${ }^{6}$ Another limitation is that mutation detection in the $\mathrm{SMN}^{\mathrm{T}}$ gene is relatively technically difficult. Although a few of the $S M N^{T}$ mutations identified have now been found in more than one patient, there is no single common mutation which can be tested. In addition, $S M N^{T}$ mutations have been identified in at least four different exons of the gene; there is not one mutational hotspot which could be easily screened. The presence of the copy gene $\left(\mathrm{SMN}^{\mathrm{C}}\right)$ also complicates $\mathrm{SMN}^{\mathrm{T}}$ mutation detection. Since $S M N^{T}$ and $S M N^{C}$ are only distinguished by single nucleotide sequence changes in exons 7 and 8, either RT-PCR or long PCR based strategies must be used to show that any mutation identified exists in $S M N^{T}$ and not $S M N^{C}$. Although mutation analysis of the $S M N^{\mathrm{T}}$ gene is not as straightforward as for some genes, the actual quantity of patients to be screened is significantly reduced by the initial dosage assay and the number of $S M N^{\mathrm{T}}$ exons to be analysed (nine) is feasible. This protocol of initial $S \mathrm{SN}^{\mathrm{T}}$ gene dosage analysis followed by mutation detection allows identification of SMA compound heterozygotes (patients lacking one copy of $S M N^{\mathrm{T}}$ and having another mutation in their other copy), thereby increasing the sensitivity of SMA molecular diagnosis.

We are grateful to all of the SMA families who have so kindly participated in our studies. This research was funded by grants from the Muscular Dystrophy Association (MDA) and Families of SMA. We are also grateful for the photograph

1 Pearn J. Classification of spinal muscular atrophies. Lancet 1980;i:919-22.

2 Munsat TL, Davies KE. Meeting report. International SMA Consortium meeting. Neuromusc Disord 1992;2:423-8.

3 Lefebvre S, Burglen L, Reboullet S, et al. Identification and characterization of a spinal muscular atrophy-determining gene. Cell 1995;80:155-65.

4 Roy N, Mahadevan MS, McLean M, et al. The gene for neuronal apoptosis inhibitory protein is partially deleted in individuals with spinal muscular atrophy. Cell 1995;80:16778.

5 Thompson TG, DiDonato CJ, Simard LR, et al. A novel CDNA detects homozygous microdeletions in greater than $50 \%$ of type I spinal muscular atrophy patients. Nat Genet 1995;9:56-62.

6 Bussaglia E, Clermont O, Tizzano E, et al. A frame-shift deletion in the survival motor neuron gene in Spanish spinal muscular atrophy patients. Nat Genet 1995;11:335-7.

7 Parsons DW, McAndrew PE, Monani UR, Mendell JR, Burghes AHM, Prior TW. An 11 base pair duplication in exon 6 of the SMN gene produces a type I spinal muscula atrophy (SMA) phenotype: further evidence for SMN as the primary SMN-determining gene. Hum Mol Genet 1996;5:1727-32.

8 Brahe C, Clermont O, Zappata S, Tiziano F, Melki J, Neri G. Frameshift mutation in the survival motor neuron gene in a severe case of SMA type I. Hum Mol Genet 1996;5:1971-6.

9 Burglen L, Patel S, Dubowitz V, Melki J, Muntoni F. A novel point mutation in the SMN gene in a patient with type III spinal muscular atrophy. First Congress of the World Muscle Society 1996. London: Elsevier, 1996:S39.

10 McAndrew PE, Parsons DW, Simard LR, et al. Identification of proximal spinal muscular atrophy carriers and tion of proximal spinal muscular atrophy carriers and
patients by analysis of $\mathrm{SMN}^{\mathrm{T}}$ and $\mathrm{SMN}^{\mathrm{C}}$ gene copy patients by analysis of $\mathrm{SMN}^{\mathrm{T}}$ and $\mathrm{SMN}$

11 Talbot K, Ponting CP, Theodosiou AM, et al. Missense mutation clustering in the survival motor neuron gene: a role for a conserved tyrosine and glycine rich region of the protein in RNA metabolism? Hum Mol Genet 1997;6:497500

12 Hahnen E, Schönling J, Rudnik-Schöneborn S, Raschke H, Zerres K, Wirth B. Missense mutations in exon 6 of the survival motor neuron gene in patient with spinal muscular atrophy (SMA). Hum Mol Genet 1997;6:821-5.

13 Rochette CF, Surh LC, Ray PN, et al. Molecular diagnosis of non-deletion SMA patients using quantitative PCR of SMN exon 7. Neurogenetics (in press).

14 van der Steege G, Grootscholten PM, van der Vlies P, et al. PCR-based DNA test to confirm clinical diagnosis of autosomal recessive spinal muscular atrophy. Lancet 1995;345 985-6. 